\section{Contingencies of Reinforcement}

Dennis Mozingo

Integrated Behavioral Solutions, Atlanta, GA, USA

\section{Definition}

Contingencies of reinforcement, in their simplest form, are comprised of antecedents (events that occur immediately before a behavior), responses or behaviors, and consequences (events that occur immediately after a behavior). The term contingencies refers to the relationship or interrelationship (Skinner 1969) between these events. Reinforcement refers to consequences that increase the probability of the behavior occurring again under similar circumstances. Thus, contingencies of reinforcement describe an antecedent-behavior-consequence link in which the consequence increases the likelihood that a behavior will occur again in the presence of an antecedent. Contingencies of reinforcement are a key component in applied behavior analysis (ABA) approaches to the treatment of autism spectrum disorders (ASD). For example, discrete trial teaching includes the presentation of an antecedent (an instruction, often referred to as a discriminative stimulus when it comes to occasion a specific response under specific conditions), the learner's response, and the presentation of reinforcement. In the case of teaching verbal (or social) behavior with learners with ASD, written or pictorial rules may be used for effectively initiating a social greeting. The rules serve an antecedent function that may occasion the behavior, in the absence of a history of reinforcement. When the behavior is exposed to naturally occurring contingencies, such as a smile in response to eye contact, a shaping process may occur, leading to behavior shaped (better eye contact during a greeting) and maintained by the contingencies of reinforcement, rather than the rule. The behavior required by the rule must be maintained by consequences (part of the contingency) to be effective - an effective rule is supported by the contingencies of reinforcement.

\section{See Also}

- Negative Reinforcement

- Operant Conditioning

- Positive Reinforcement

\section{References and Reading}

Cooper, J. O., Heron, T. E., \& Heward, W. L. (2007). Basic concepts. In J. O. Cooper, T. E. Heron, \& W. L. Heward (Eds.), Applied behavior analysis (2nd ed., pp. 24-46). Upper Saddle River: Pearson.

Johnson, J. M. (2014). Radical behaviorism for ABA practitioners (pp. 110-113). Cornwall on Hudson: Sloan.

Skinner, B. F. (1969). Contingencies of reinforcement: A theoretical analysis. New York: Meredith. 